\title{
A Summary of Studies on Bon and Its Relationship with Buddhism
}

\author{
Sangdrag Tsering \\ School of History and Culture, Northwest Minzu University, Lanzhou, China
}

\begin{abstract}
Bon Religion is the original religion of the Qinghai-Tibet Plateau. Today there are still Bon beliefs or cultural phenomena influenced by Bon Religion in areas where Tibetans live. This is an important content of Tibetology research today. Predecessors' research on Bon Religion mainly focused on three major issues: the birth of Bon Religion, the historical staging of Bon Religion, and the relationship between Buddhism and Ben religion. Many results have been achieved. However, these are far from enough in terms of the research value of Bon Religion itself. The research on the time and place of the birth of Bon Religion has not yet been concluded. The main results are concentrated on the research of macroscopic issues, and the research on specific issues is insufficient. In response to these issues, researchers should pay attention to the re-discussion of existing results, use the method of combining literature and field investigations to pay more attention to specific regional issues, and at the same time strengthen the use of multiple languages.
\end{abstract}

Keywords: Bon Religion, Relationship between Buddhism and Ben religion, Summary.

\section{Introduction}

Bon Religion is the original religion of the Qinghai-Tibet Plateau. It is a religion believed by all the people in the early regimes of the plateau, such as Zhangzhung, Sumpa, and Tubo. It has certain primitive religious characteristics. As the Tubo Dynasty conquered the plateau, Buddhism began to spread, and gradually occupied a dominant position in the beliefs of the people. However, due to its long history and the continuous reforms and adaptations of Bon Religions throughout the ages, even in an era when Tibetan Buddhism was absolutely dominant, Bon Religion still existed stubbornly and profoundly affected the spiritual world, social cultural and life of the Tibetan people. It also played a very important role in the birth and development of Tibetan Buddhism. However, in order to gain a thorough and complete understanding of Tibetan culture, it is indispensable to study the history and culture of Bon Religion.

\section{The Birth of Bon Religion}

\subsection{The Interpretation of "Bon"}

The word "Bon" of the Bon Religion has many interpretations in Tibetan. In Skyogs Ston Ren Chen Tashi's Lilac Tent-Differentiation and Analysis of Ancient and Modern Tibetan Words[1], "Bon" is interpreted as "chant", "recite" or "produce". The famous Italian Tibetologist Mr. Nankanurbu believes that "Bon" is an ancient Tibetan word, which means to repeat it in modern terms. Tracing back to the root of the title "Bon Religion", in ancient times those Bon po (Bon believers) used mighty spells, namely chanting spells, to eliminate disasters and subdue the invaders of themselves and others, and thus get this title. Norbu Tsering proposed in the article Tibetan Primitive Religion-Everlasting Bon Religion[2] that as a primitive religion, Bon Religion may have a close relationship with "chant" and "recite". Obviously, this definition is based on the basic historical fact that primitive beliefs must repeat their respective mantras during the ceremony, is just to distinguish these primitive beliefs by adding the word "Bon" after their address words, such as "klu
Bon", "btsan Bon", "lha Bon" and so on.

Tsering Thar mentioned in Tubo's Bon Religion and "srid pa spyi mdos"[3] that the Tibetan word "bon" had different transliterations in Chinese. First, Mr. Changshou Ma translated it into Bojiao(钵教) in the 1940s[4]. Since then, especially after the $1980 \mathrm{~s}$, different transliterations such as “本教”, “笨教”, “黑教” and “苯教” have appeared one after another. White Annals mentioned that "according to the opinion of the Bon believers, the place formerly known as 'bon' later evolved into a bod."[5] Ngawang Gyatso said in A Discussion on the Basic Meaning and Formal Features of Sridpa Bon[6] through the analysis of the word "bon" in Tibetan literature, it is proposed that the word "bon" has two main meanings. As a noun, it is the name of Bon and Bon rituals; as a verb, it refers to rituals, or the meaning of explanation.

\subsection{The birth of Bon Religion}

In academia, the birthplace of Bon Religion has always been a controversial issue. Tsering Thar mentioned in Tubo's Bon Religion and "srid pa spyi mdos"[7]: "Judging from the traditional literature of Bon Religion, the Tibetan people's overall memory of Bon in the early history has always believed that Bon came from the far west, and Stag Gzig ${ }^{i}$ has always been regarded by Bon Religions as a country related to the birthplace of Bon Religion." However, with the continuous discovery of the Bon Religion literature, it has gradually emerged contrary viewpoints to the above-mentioned viewpoint that the birthplace of the Bon Religion is the Stag Gzig. srid pa spyi mdos[8] demonstrates the relationship between Gshenrab Mibo and Gangdisi Mountain, and further describes an important message, that is, Gshenrab Mibo lives in 'ol mo Lungring, and this 'ol mo Lungring is located in area centered on Gangdisi Mountain is not a Stag Gzig but within Tubo. Although this document does not state that Gshenrab Mibo was born here, the description of this sacred place and the use of it as the residence of Gshenrab Mibo are enough to show that this 
place is the birthplace of Bon. Shi Shuo elaborated on the birthplace of Bon Religion in A Brief Discussion on the Connotation and Evolution of the Bon Religion[9]. He believed that Bon Religion was a general term for the religions that existed and prevailed in Tibet before the introduction of Buddhism. However, according to historical records of Bon Religion, Bon Religion seems to be a religion introduced from Zhangzhung or a certain area in the west.

As for the specific birthplace of Bon Religion, Stag Gzig was mentioned in the History of Bon[10] by Samten G. Karmy, and Kashmir, Borud (Now Gilgit) and Zhangzhung were mentioned in Thu'u Kwun Grub Mtha'[11] by Thu'u Kwun Lobzang Chokyi Nyima. This shows two possibilities. One is: Bon Religion is a foreign religion. It was first introduced into the Zhangzhung area from a country outside of western Tibet, and then spread to all parts of Tibet via Zhangzhung. The other is: Bon Religion is a primitive religion that originated from Zhangzhung, but this religion was strongly influenced by foreign religions and cultures in its later development, and it has been absorbed and accepted in large quantities in geography and teachings from foreign religions. Shi Shuo said: "Which of these two possibilities is more reliable is still difficult to determine. But one thing can be confirmed that the Bon Religion, which was popular in Tibet before the introduction of Buddhism, does have some foreign religious characteristics. Popular opinion believes that the dualism of Zoroastrianism (called 'Xianjiao(祅教)' in Chinese historical records), which was popular in ancient Persia and Central Asia in the 3rd and 7th centuries AD, is closely related to Bon." Japanese scholar Takao Moriyasu also believes in Tibet in the History of Central Asia[12]: In the teachings, legends and customs of Bon, it can be found that in addition to the Indian factor, there are also strong Iranian factors. It is said that this is result of the self-assimilation in western Tibet of Bon, if so, the support of Bon's exchanges with the Iranian world in western Tibet should at least be traced back to the establishment of the Tubo Dynasty (before the 6th century) ... Therefore, it can also be said that in the Bon the fact that there is an Iranian factor is the best proof that Tibet and Central Asia had exchanges before the 6th century.

The missionary Ye Changqing ii believes that "there is no doubt that Bon is a relic of the original natural worship in Tibete, which contains most of the things common to Eastern religions."[13] Italian scholar Giuseppe Tucci in The Religion of Tibet [14] Chapter 7 "The Bon Religion in Tibet" pointed out that the apparently older elements of Bon Religion also proved its element of Iranian belief. According to all indications, it especially has the sensitive influence exerted by the Zurvan iii belief. Shen Xiaohu and Ngawang Gyatso elaborated the missionary Ye Changqing's analysis of the origin of Bon and the names of Bon believers in the Bon Religion in Sichuan and Tibet in the Eyes of Missionaries [15]. Ye Changqing believed that Bon Religion was related to ancient Persia, and he listed the evidence is that Bon believers believe that Bon Religion originated from "Tazing"iv, that is, Persia.

\section{The Relationship between Buddhism and Bon}

The history books of Bon believe that the development of Bon Religion has gone through two stages, namely the original Sridpa Bon stage and the later Yungdrung Bon stage. In $A n$ Overview of the Relationship between Bon Religion and Tibetan Buddhism[16], Ngawang Gyatso used Bon's recognition of Buddhism and Buddhism's attitude towards Bon, as well as the relationship between Bon and the various sects of Tibetan Buddhism. He believed that the primitive Sripa Bon has little to do with Buddhism, while the Yungdrung Bon is a sect of Buddhism. It is proposed that among the sects of Tibetan Buddhism, the Nyingma Sect is the sect most similar to the Bon. And explained the relationship between the Bon Religion and the various sects of Tibetan Buddhism: The relationship between the Bon Religion and the various sects of Tibetan Buddhism is not close, but it is also very close. There are many examples that the two religions being mentors and apprentices each other. Mutual study tours and debates btween monastery have become the norm. From the initial struggle to the later integration, it is actually a microcosm of the development of Bon Religion. The institutionalization of Bon Religion was actually completed in the process of its Buddhistization.

In the article A Brief Discussion on the Connotation and Evolution of the Bon[17] Shi Shuo mentioned that the primitive religion in Tibet called it "Bon", then This kind of primitive "Bon" intersects with the Yungdrung Bon, which came from Zhangzhung and may be influenced by the other religion, and the two have mixed and merged to a considerable extent. Therefore, we can conclude that it is precisely because the Yungdrung Bon has a more complete theoretical system than the primitive "Bon", the result of the fusion of the two has led to the theorization of the original "benzene" and the Localization of Yungdrung Bon. After Buddhism was introduced, Bon and Buddhism crossed again. On the one hand, this kind of convergence led to Buddhism's large absorption and accommodation of Bon elements and gradually "Tibetaization", and eventually formed Tibetan Buddhism. On the other hand, the original Bon has also undergone major changes under the influence of Buddhism, becoming a religious genre with a strong Buddhist color and coexisting with the various schools of Tibetan Buddhism. But at the same time, Shi Shuo also proposed that because Bon Religion is a very folk religion, it determines that it cannot completely and completely intersect with Buddhism. Therefore, after Buddhism is introduced, the mutual influence and integration of Buddhism and Bon would become mainstream, but many factors such as the customs and rituals of Bon Religion are still preserved and accumulated in the lives of ordinary people. In some remote, closed, and places where Buddhism is difficult to spread in southeastern Tibet and Kham, Bon Religion has been continued with its original appearance to a large extent. So, although the intersection with Buddhism has caused a major change in the face of Bon Religion, the original Bon Religion has not disappeared as a result, but has been further localized. 
Thu'u Kwun Lobzang Chokyi Nyima said in Thu'u Kwun Grub Mtha[18] that "Bon and Buddhism are originally contradictory one. Buddhism is mixed with Bon, and Bon is also mixed with Buddhism." Therefore, the intersection of Bon and Buddhism in a sense, it can be said to have led to the "generalization" of the original Bon Religion. The Bon Religion that merged with Buddhism not only penetrated and merged widely into the various schools of Tibetan Buddhism, but also the continued Bon sects also lost its original appearance. Due to the influence of Buddhism. In other words, Mian Buddhism has gained a foothold in Tibetan society by absorbing the indigenous cultural elements of Bon Religion, and Bon Religion has also made itself more systematic and organized by drawing lessons from Buddhism, and bacom a ralatively perfect religious sects which can compete with and coexist with the various schools of Tibetan Buddhism.

Shen Xiaohu and Ngawang Gyatso pointed out in The Bon Religion in the Sichuan-Tibet Region from the Perspective of Missionaries[19]. If the dispute between Buddhism and Bon is viewed in the macro-historical context, after a long period of development, a situation of "Buddhism in Bon and Bon in Buddhism" has been formed between the two, especially in the later period of the Yungdrung Bon Religion. As Cunningham said in the report: "Today, the Gelugpa, Nyingma and Bon Religions in the Sichuan-Tibet area coexist, share the living Buddha reincarnation system, and use rituals to expel ghosts and cure diseases."

Tsering Thar believes that in the The Origin and Analysis of the Historical Syllogism of Bon Religion[20], the "Khri srong lde btsan exterminates Bon Religion" in the second half of the 8th century $\mathrm{AD}$ and the "Glang dar ma exterminates Buddhism" in the first half of the 9th century AD. Only more than half a century apart, the Bon Religion and Buddhism have been destroyed one after another, and they have been devastated. Coupled with the collapse of the Tubo dynasty caused by the "Glang dar ma exterminates Buddhism", the entire Qinghai-Tibet Plateau was in a situation where there was no leader and lasted for more than two centuries. Such a political structure provides an excellent respite for the two religious traditions that have been destroyed. After more than two centuries of painstaking efforts, both Bon Religion and Buddhism have developed to a certain extent, especially Buddhism, because the capital left by the incomplete "Glang dar ma exterminates Buddhism" has given them long-term development conditions. The two religious traditions have absorbed and repelled each other in their development. Behind the historical phenomenon of the dispute between Buddhism and Bon is the integration of these two cultural traditions in terms of theory and rituals. In addition to the exclusion of the two cultures, the deep absorption and integration of the two cultures of Buddhism and Bon is the source of development of Tibetan civilization. From the perspective of civilization formation, the history of the struggle between Buddhism and Bon is the history of mutual integration and absorption between the two sides.

\section{The Historical Staging of Bon}

There have been many different discussions about the historical staging of Bon Religion in recent years. Tsering thar conducted an in-depth analysis of the famous Bon historical syllogies, namely brdol Bon, 'khyar Bon and rkyud Bon in The Origin and Analysis of the Historical Syllogism of Bon[21], from the proposal and origin of the syllogism. The historical background and the main content of this theory are discussed in three aspects. It is believed that the theory was actually proposed by the Kagyu school scholar 'Jig Rten Mgon Po as early as 600 years ago, rather than by the master Thu'u kwun as believed by the academic circles in the past. The article analyzes the ins and outs of this academic viewpoint and its influence on Tibetan studies at home and abroad, as well as re-critiques its actual connotation and facts. At the same time, the author believes that this syllogism is a definition given by Buddhist scholars to the historical stages of Bon Religion, rather than the orthodox description of Bon Religion. Bon Religions do not recognize the rationality of this syllogism. Although this famous syllogism has its aspects that are consistent with historical facts, especially the three contents of brdol Bon, 'khyar Bon and rkyud Bon are obviously based on historical facts, but as a historical narrative of a religious tradition, it is still Lack of continuity and completeness. Therefore, in the absence of historical documents of Bon Religion, it is far-fetched to ignore the main line of Bon historical development and use some events in the history of Bon Religion as signs to describe the historical stages of Bon Religion.

Ngawang Gyatso sorted out the issue of the historical staging of Bon Religion in On the issue of the historical staging of Bon Religion[22], mainly including the dividing method of Bon classics, the traditional three-division method of Tibetan Buddhism, and the modern scholars' method and so on. In the Bon classics, the history of the development of Bon Religion is generally divided into two stages, namely Gyud Bon and Yungdrung Bon, and Yungdrung Bon is divided into three stages, as contained in Rgyal Rabs Bon Kyi 'Byung Gnas[23] "The rise and fall of the Bon Religion mainly experienced three stages: the initial promotion stage, the intermediate stage of destruction, and the final stage of prosperity." The promotion stage mainly describes the spread of Gshenrab Mi bo's teachings in the world and in Tibet (the pre-deployment period of Bon Religion); the intermediate destruction stage mainly describes the "Extinguish Buddhism" in the period of Gri Gum Btsan Po and Kri Srong Lde btsan and Its influence (the middle propagation period of Bon Religion); the final stage of prosperity mainly talks about the unearth Terma of "gshen chen klu dga" and the revival of the Bon Religion (the latter period of Bon Religion). In the article, he proposed his own dividing method, namely the primitive Sridpa Bon Religion stage, the Buddhist Bon -doped variant Bon Religion stage, and the Buddhistized Yungdrung Bon Religion stage. The new historical staging method demonstrates that the conversion of primitive folk beliefs into highly Buddhist Bon Religion was not completed overnight.

Kang Skal Bzang Ye Shes's Bon Religion-The Source of Tibetan Traditional Culture[24] gave a comment on the formation, creation, and development of Tibetan Bon 
Religion, the characteristics of the beliefs of Bon Religion, the development of factions, and the stages of evolution. The main deities of the Bon Religion and the influence of the Bon teacher Gshenrab Mibo Che on the history of Tibetan society have been discussed and studied.

Tsering Thar discussed the development of Bon Religion from ancient times to the time of the Zhangzhung Kingdom in The First Spread of Bon Religion in Tubo and Its Relationship with Buddhism[25]. He believes that Bon Religion has gradually unified from various primitive religious beliefs that did not belong to each other to the name of Yungdrung Bon Religion, becoming a complete belief system. The above viewpoints are of great significance to the study of the historical staging of Bon Religion.

\section{Current Problems in the Study of Bon Religion and Reflections on These Problems}

\subsection{Problems in the Study}

By combing the current study status of Bon Religion in academia, it can be concluded that there are the following problems in the study of Bon Religion in academia.

First of all, from the overall situation of Bon Religion research, compared with other aspects of Tibetan studies, there are fewer research results on Bon Religion, and the research results are mainly in the form of papers, and there are few monographs. Human research results tend to be consistent, and innovative research is scarce. Secondly, judging from the content of the Bon Religion, the academic research on Bon Religion basically covers all aspects, but there is no definite and unified answer to the research on the birthplace of Bon Religion and the time of its initial emergence, and there is a lack of comparative study of the relationship with other religions. Finally, most studies on Bon Religion are conducted from the perspective of macro-theoretical concepts, and there are few regional case studies of Bon Religion in a certain community. These macro-theoretical systems are mainly the collation and application of Tibetan historical records and unearthed archaeological materials, mainly from the research methods of historical philology, and seldom use the first-hand materials obtained through field investigations.

\subsection{Thoughts on Future Research}

Based on the above-mentioned problems in the study of Bon Religion, the author puts forward some thoughts on the study of Bon Religion in the future.

First, the researcher's perspective on the Bon Religion can be further expanded, and the research results of the predecessors should be further considered. While actively adopting the research results of the predecessors, they should also put forward their own views and find novel entry points for in-depth research to supplement the research content of Bon Religion. Second, in terms of research methods, attention should be paid to historical materials of Tibetan religious documents and field investigation methods should be widely used to obtain first-hand data for empirical research. Combine ancient Tibetan books with field surveys to carry out various comparative studies to conduct in-depth research on Bon Religion. Third, from the research conditions of researchers, the study of Bon Religion needs to be applied to Chinese, Tibetan, English and other languages in the use of specific literature materials, and in the comparison of multi-language and multi-regional literature. Clarify some controversial issues in the study of Bon Religion. This puts high demands on the language ability of Bon researchers, and more efforts should be made in this area in the future.

\section{References}

[1] Syogs Ston Rin Chen bkra Tashi: Lilac Tent-Differentiation and Analysis of Ancient and Modern Tibetan Words. Beijing: The ethnic publishing house, 1982.

[2] Norbu Tsering: The primitive religion of Tibet-Bon Religion, Journal of Qinghai Minzu University (Social Science). No. 3, 1999, pp. 22-25.

[3] [7] Tsering Thar: Tubo's Bon Religion and "srid pa spyi mdos", China Tibetology. No. 3, 2008, pp. 63-70.

[4] Changshou Ma: The Source of Bo Religion, Ethnological Research Collection. China, 1943, pp. 25-31.

[5] Dge 'Dun Chos 'Phel: The White Annals, Beijing: The ethnic publishing house, 2002, pp. 12.

[6] Ngawang Gyatso: A Discussion on the Basic Meaning and Formal Features of Sridpa Bon, Journal of Tibet University (Social Science). No. 1, 2013, pp. 117-122.

[8] Manuscripts collection by Italian Institute of Asian and African Studies: ya gi skyid po'I yul/ (nyms) dga' bag re bro/ chu gyal zhi (bzhi) 'du mgo'i rgya ti se'i mdun/ tsho (mtsho) gyal ma pham 'gram/ 'ol lung gyu yi mkhar/ bzhugs gnas ngo re mtshar/ de 'dra'i sku khar (mkhar) na/ su bzhugs su mi bzhugs/bzhugs pa gshen gyi lha/ gshen rab myi bo che/

[9] [17] Shi Shuo: A Brief Discussion on the Connotation and Evolution of the Bon Religion, Journal of Xizang Minzu University (Social Science). No. 4, 1996, pp. 43-46.

[10] Samten G. Karmy, translated by Wang Yao and Chen Guan Sheng: History of Bon.

[11] [18] Thu'u Kwun Lobzang Chokyi Nyima, translated and annotated by Liu Li Qian: Thu'u Kwun Grub Mtha'. Lhasa: The Tibet people's Pulblishing House, 1984.

[12] Takao Moriyasu: Tibet in the History of Central Asia, Tibetan Studies. No. 4, 1987, pp. 110-112.

[13] J. H. Edgar: The Marches of the Mantze. China Inland Mission, 1918, p.62.

[14] Giuseppe Tucci, Translated from German and Italian by Geoffrey Samuel: The Religion of Tibet, Great Britain, pp. 213-248.

[15] [19] Shen Xiaohu, Ngawang Gyatso: Bon Religion in Sichuan and Tibet in the Eyes of Missionaries, China Tibetology, No. 3, 2013, pp. 96-101.

[16] Ngawang Gyatso: An Overview of the Relationship between Bon Religion and Tibetan Buddhism, Journal of Southwest Minzu University (Humanities and Social Science). No. 4, 2011, pp. 72-76. 
[20] [21] Tsering Thar: The Origin and Analysis of the Historical Syllogism of Bon Religion, China Tibetology. No. 4, 2008, pp. 63-70.

[22] Ngawang Gyatso: The issue of the historical staging of Bon Religion, Journal of North Minzu University (Philosophy and Social Science). No. 5, 2014, pp. 7-12.

[23] Khok Po Blo Gros Thoks Med: Rgyal Rabs Bon Kyi 'Byung Gnas. manuscript.

[24] Kang Skal Bzang Ye Shes: Bon Religion-The Source of Tibetan Traditional Culture, Journal of Sichuan University (Philosophy and Social Science). No. 5, 2003, pp. 59-62.

[25] Tsering Thar: The First Spread of Bon Religion in Tubo and Its Relationship with Buddhism, China Tibetology, No. 2, 2006, pp. 243-250.

\footnotetext{
i Sometimes it is written as "ta zig" in Tibetan literature, and it is called "da shi (大食)" in Chinese history books, which is later called Persia, which is now Iran.

ii James.Huston Edgar (1872-1936) was an important missionary in edge of Sichuan during the late Qing Dynasty and the Republic of China. He wrote many books and made some achievements in anthropology, geography, archaeology and religion. He also investigated the religious belief of Sichuan Jiarong Tibetan and Baishi worship. According to research, his Chinese name is Ye Changqing and his nationality is Australia.

iii Zurvan, a god of time in Iranian religion.

iv Another way of writing "Tazig", this is likely to be a clerical error by the author.
}

\section{Author Profile}

Sangdrag Tsering (1995-), a graduate student majoring in the history of Chinese ethnic history in the School of History and Culture, Northwest Minzu University, his main research direction is the Tibetology and history of Northwest ethnic groups. 